\title{
Cardiovascular System Findings Original Result
}

National Cancer Institute

\section{Source}

National Cancer Institute. Cardiovascular System Findings Original Result. NCI Thesaurus.

Code C123983.

The outcome of the cardiovascular system assessment as orig inally received or collected. 